\title{
Diet and other factors in the aetiology of diverticulosis: an epidemiological study in Greece
}

\author{
O MANOUSOS, N E DAY, A TZONOU, C PAPADIMITRIOU, A KAPETANAKIS, \\ A POLYCHRONOPOULOU-TRICHOPOULOU, AND D TRICHOPOULOS
}

From the International Agency for Research on Cancer, Lyon, France, Department of Hygiene and Epidemiology, Athens Medical School, Department of Gastroenterology, Evangelismos Hospital, Athens, and Department of Nutrition and Biochemistry, Athens School of Hygiene, Athens, Greece.

SUmmary A case control study exploring the role of diet and other biosocial factors in the aetiology of diverticulosis was undertaken in Athens, Greece, in 1981-1982. One hundred consecutive cases with radiologically confirmed diverticulosis and 110 control patients with fractures or other orthopaedic disorders were submitted to a structured interview, including frequency of consumption of about 80 food items. The main positive findings were, (i) the cases reported significantly less frequent consumption of vegetables, brown bread and, to a lesser extent, potatoes and fruits, and (ii) the cases reported significantly more frequent consumption of meat and, to a lesser extent, milk, and milk products. The difference in risk between those people who frequently consume vegetables but rarely consume meat, and those who rarely consume vegetables and frequently consume meat, was almost 50 -fold.

Diverticulosis is considered to be the commonest disorder of the large bowel in most of the developed countries of the world, including Britain, ${ }^{1}$ USA, ${ }^{2}$ and Greece ${ }^{3}$ although the absolute prevalence of the disease in Greece is considerably lower. ${ }^{3}$ On the basis of geographic correlations and time trends Painter and Burkitt ${ }^{4}$ suggested that the condition may be caused by an inadequate intake of dietary fibre, a hypothesis supported by experimental studies in rats, ${ }^{56}$ two controlled epidemiologic studies in Britain, ${ }^{17}$ and at least one randomised therapeutic trial aimed at alleviation of symptoms. ${ }^{8}$ Although the fibre deficiency hypothesis has been widely quoted there is some conflicting evidence. Workers in Africa reported an appreciable frequency of diverticulosis in populations on traditional high fibre African diet $;{ }^{9} 10$ no effect of fibre was noted in another randomised therapeutic trial $;{ }^{11}$ intestinal transit time was reported to be shorter in patients with diverticulosis than in normal subjects $;{ }^{12}$ and of the two British epidemiologic studies the results of one were clear-cut only among women. Several authors, including Mendeloff, ${ }^{13}$ have criticised the simple fibre deficiency hypothesis

Address for correspondence: Dr N F Day. International Agency for Research on Cancer. 150 cours Albert Thomas, 69372 Lyon Cedex 08. France

Received for publication 3 August 1984 as too simplistic in a complex world of multifactoral disease causation. We have undertaken a case control study of diverticulosis in Athens. The substantial dietary variability currently observed in the Greek population creates a favourable situation for a case control epidemiologic investigation of diseases with suspected nutritional aetiology, as shown recently in a study of the aetiology of colorectal cancer in the same population. ${ }^{1+}$

\section{Methods}

PATIENTS AND CONTROLS

Between May 1981 and July 1982, 100 patients with diverticulosis were hospitalised in the largest teaching hospital of Athens. These cases were diagnosed on the basis of barium enema findings (at least three clearly identifiable diverticula); the diagnostic radiological examination was requested by the attending physician for the evaluation of dominant or coexisting abdominal symptoms of recent onset (within three years). The 100 cases formed a series of consecutive patients in whom diverticulosis was diagnosed for the first time; for 25 of them diverticulosis was the only diagnosis, whereas for the remaining 75 patients, diverticulosis was diagnosed together with another disease. The associated diseases were: bronchitis, pneumonia and 
other acute febrile diseases (11), anaemia and other diseases of the blood (seven), chronic bronchitis and emphysema (six), coronary heart disease (six), congestive heart failure (five), cholecystitis and cholelithiasis (five), renal diseases (five), endocrine disorders (four), osteoarthrosis (four), hiatus hernia (three), hernias (other) (three), haemorrhoids (three), varicose veins and thrombophlebitis (three), gynaecologic diseases (two), collagen diseases (two), drug allergy and skin diseases (two), viral hepatitis (two), neurotic disorders (two). The control group consisted of 110 accident or other orthopaedic patients hospitalised during the same period in the same hospital or in the Athens Hospital for Orthopaedic Disorders. The control patients were equally distributed between the two source hospitals; it was not possible to find a sufficient number of eligible control subjects in the first hospital for concurrent interviews. The control patients had to have no known diverticulosis, other gastrointestinal disorder, or appreciable abdominal symptoms, but for obvious ethical reasons they were not submitted to a barium enema. All cases and control patients had to be free from gastrointestinal diseases necessitating a special diet. Very young orthopaedic patients were not included in the control series, but explicit age or sex matching was not attempted, and patients with diabetes (12 cases and 10 controls) were not excluded from either series.

All case and control patients were interviewed in the hospital wards by the same person (AK) who is a trained gastroenterologist; there were no refusals. Data concerning demographic, socio-economic and biometric variables were recorded and detailed dietary histories were obtained. Specifically all patients were asked to indicate the average frequency of consumption (per month, per week or per day, as the case may be) before the onset of the present disease of about 80 food items or beverage categories - that is, beer, wine, brandy, etc. Repeat interviews of 40 control patients by another interviewer, after more than two years from the first interview, generated correlation coefficients between 0.50 (cereals) and 0.68 (meat, fish and eggs); therefore, the repeatability of the dietary information may be considered acceptable (data available on request).

The initial statistical analyses were based on the methods of Mantel and Haenszel, and further multivariate analyses on multiple logistic regression $^{15}$ using the GLIM statistical package. ${ }^{16}$ Food items were considered in groups as recommended by Davidson and Passmore ${ }^{17}$ and other authors (Table 1), as well as individually. The frequency of consumption of the different food
Table 1 Food items considered in the dietary questionnaire, classified into food groups

\begin{tabular}{|c|c|}
\hline Food group & Food items \\
\hline G1: Cereals & $\begin{array}{l}\text { White bread, brown bread, pastas. } \\
\text { meatless pies, rice }\end{array}$ \\
\hline G2: Starchy roots & Potatoes \\
\hline G3: Sugars and syrups & $\begin{array}{l}\text { Sugar, biscuits, chocolate, sweets with } \\
\text { syrup for example, baklava, jellies, } \\
\text { fruit glaces, spoonful sweets (Greek } \\
\text { delicacies). compote }\end{array}$ \\
\hline $\begin{array}{l}\text { G4: Pulses, nuts and } \\
\text { seeds }\end{array}$ & $\begin{array}{l}\text { Beans, fresh beans, broad beans, fresh } \\
\text { broad beans, peas, green peas, chick } \\
\text { peas. fava, lentils, nuts (various) }\end{array}$ \\
\hline G5: Vegetables & $\begin{array}{l}\text { Tomatoes, cucumbers, pumpkins and } \\
\text { courgettes, onions, aubergines, } \\
\text { cabbage, lettuce, spinach, okra, lecks, } \\
\text { dandelions, artichokes, beets, carrots. } \\
\text { mushrooms, broccoli, cauliflower }\end{array}$ \\
\hline G6: Fruits & $\begin{array}{l}\text { Water melon, melon, mandarins, } \\
\text { lemons, oranges, apples, peaches, } \\
\text { pears, grapes, apricots, cherries, } \\
\text { bananas, figs }\end{array}$ \\
\hline $\begin{array}{l}\text { G7: Meat, fish, eggs, } \\
\text { and novel protein }\end{array}$ & $\begin{array}{l}\text { Pork, veal-beef, lamb, goat, rabbit. } \\
\text { chicken, fish, salami and sausages, } \\
\text { entrails, eggs }\end{array}$ \\
\hline $\begin{array}{l}\text { G8: Milk and milk } \\
\text { products }\end{array}$ & Cheese, milk, yogurt, ice cream \\
\hline G9: Oils and fats & Butter, olives, oil \\
\hline
\end{tabular}

items was quantified approximately, in terms of the number of times per month the food was consumed, as done for example by Graham et $a l^{18}$ and Manousos et al. ${ }^{14} \mathrm{~A}$ value of 30 was assigned to food items used almost every day; a value of 10 to those used at least twice a week but not every day; a value of 4 to food items used about once a week; a value of 2 to those used at least once a month but not every week; and a value of 0 was assigned to food items used rarely or not at all. When food items were considered in groups the individual values were added and the sums were distributed into two, three or four 'levels', the objective being to create, as far as possible, levels with approximately the same number of cases and controls combined - that is, about 70 between tertiles, or about 50 between quartiles.

\section{Results}

Among the 100 cases with diverticulosis 44 were men, 66 were aged 60 or more (mean 65.4 years), 73 had gone to school for at least six years, 80 owned a private telephone, and 71 were living in Athens or another urban centre. Among the 110 control patients $46(42 \%)$ were men, $70(64 \%)$ were aged 60 or more (mean 65.3 years), $55(50 \%)$ had gone to school for at least six years, $53(48 \%)$ owned a private telephone, and $68(62 \%)$ were living in Athens or another urban centre. It is evident that 
the patients with diverticulosis are of higher socioeconomic status (as reflected in telephone ownership and years of schooling) than the control patients, whereas the case and control series have very similar age and sex distributions. Patients with diverticulosis are urban residents more frequently than control patients but the difference is not statistically significant $(p \sim 0.20)$ and is further reduced after adjustment for socio-economic status. Therefore, all subsequent comparisons were adjusted for socio-economic status (in terms of years of schooling and telephone ownership) as well as, in a routine manner, for age and sex.

Table 2 shows the distribution of cases and controls by frequency of consumption of each major food group. Two $\chi^{2}$ for trend (with one degree of freedom) are given for every distribution: one crude and one adjusted for age, sex and socio-economic status. Highly significant trends $(p<0.005)$ are evident with respect to vegetables (decreasing risk with increasing consumption) and meats (increasing risk with increasing consumption); suggestive trends are also seen with respect to cereals and starchy roots $(\mathrm{p}<0.05)$ and to fruits and milk products $(p<0 \cdot 10)$. It should be noted that cereal consumption combines consumption of white and brown bread. Further analyses, see below, indicated that the distinction is of importance.

We next examined separately the constituent food items of the above groups, restricting attention to those food items for which the respective adjusted trend was significant at the $1 \%$ level or less. Five food items were identified by this procedure (cucumber, lettuce, spinach and brown bread, as contrasted to white bread, as 'protective'; and lamb meat as 'detrimental'). A sixth item (beef meat, detrimental), although significant only at the 5\% level was included because of its high consumption frequency in most population groups in most developed countries (Table 3 ).

We introduced these six food items simultaneously into a logistic regression (controlling as before for age, sex, and socio-economic status). There is no evidence of substantial mutual confounding; the deviance is reduced by $47 \cdot 2$ (6 df) when all six items are introduced simultaneously, whereas it is reduced by a total of 58.6 when the six items are examined univariately. The logistic regression coefficients give the logarithms of the risk ratios associated with a unit increase in the monthly frequency of consumption of each of the six discriminatory food items. The results are more

Table 2 Distribution of 100 cases and 110 controls by level of consumption frequency of various food groups

\begin{tabular}{|c|c|c|c|c|c|c|c|c|}
\hline \multirow[t]{2}{*}{ Food Group ${ }^{*}$} & & \multirow[b]{2}{*}{1} & \multicolumn{2}{|c|}{ Levelt } & \multirow[b]{2}{*}{4} & \multicolumn{2}{|c|}{$\chi^{2}$ for trend on $1 d$} & \multirow{2}{*}{$\begin{array}{l}\text { If } \\
\text { (two-tailed })\end{array}$} \\
\hline & & & 2 & 3 & & Crude & Adjusted $\ddagger$ & \\
\hline Cereals & $\begin{array}{l}\text { Cases } \\
\text { Controls }\end{array}$ & $\begin{array}{l}24 \\
25\end{array}$ & $\begin{array}{l}18 \\
38\end{array}$ & $\begin{array}{l}32 \\
27\end{array}$ & $\begin{array}{l}26 \\
20\end{array}$ & $2 \cdot 0$ & $4 \cdot 0$ & $<0 \cdot 05$ \\
\hline $\begin{array}{l}\text { Starchy } \\
\text { roots }\end{array}$ & $\begin{array}{l}\text { Cases } \\
\text { Controls }\end{array}$ & $\begin{array}{l}54 \\
39\end{array}$ & $\begin{array}{l}46 \\
71\end{array}$ & & & $5 \cdot 3$ & $4 \cdot 0$ & $<0.05$ \\
\hline $\begin{array}{l}\text { Sugars and } \\
\text { syrups }\end{array}$ & $\begin{array}{l}\text { Cases } \\
\text { Controls }\end{array}$ & $\begin{array}{l}33 \\
49\end{array}$ & $\begin{array}{l}37 \\
32\end{array}$ & $\begin{array}{l}30 \\
29\end{array}$ & & $1 \cdot 8$ & $1 \cdot 3$ & $\simeq 0 \cdot 25$ \\
\hline Pulses, etc & $\begin{array}{l}\text { Cases } \\
\text { Controls }\end{array}$ & $\begin{array}{l}41 \\
38\end{array}$ & $\begin{array}{l}34 \\
42\end{array}$ & $\begin{array}{l}25 \\
30\end{array}$ & & $0 \cdot 6$ & $0 \cdot 3$ & $\simeq 0.58$ \\
\hline Vegetables & $\begin{array}{l}\text { Cases } \\
\text { Controls }\end{array}$ & $\begin{array}{l}36 \\
20\end{array}$ & $\begin{array}{l}29 \\
26\end{array}$ & $\begin{array}{l}21 \\
31\end{array}$ & $\begin{array}{l}14 \\
33\end{array}$ & $13 \cdot 4$ & $15 \cdot 8$ & $<0.0005$ \\
\hline Fruits & $\begin{array}{l}\text { Cases } \\
\text { Controls }\end{array}$ & $\begin{array}{l}34 \\
34\end{array}$ & $\begin{array}{l}34 \\
35\end{array}$ & $\begin{array}{l}32 \\
41\end{array}$ & & 0.4 & $2 \cdot 7$ & $\simeq 0 \cdot 10$ \\
\hline Meats, etc & $\begin{array}{l}\text { Cases } \\
\text { Controls }\end{array}$ & $\begin{array}{l}14 \\
30\end{array}$ & $\begin{array}{l}27 \\
35\end{array}$ & $\begin{array}{l}29 \\
25\end{array}$ & $\begin{array}{l}30 \\
20\end{array}$ & $8 \cdot 1$ & $8 \cdot 5$ & $<0 \cdot 005$ \\
\hline $\begin{array}{l}\text { Milk and } \\
\text { milk products }\end{array}$ & $\begin{array}{l}\text { Cases } \\
\text { Controls }\end{array}$ & $\begin{array}{l}26 \\
43\end{array}$ & $\begin{array}{l}33 \\
35\end{array}$ & $\begin{array}{l}41 \\
32\end{array}$ & & $5 \cdot 2$ & $3 \cdot 0$ & $\simeq 0.08$ \\
\hline $\begin{array}{l}\text { Oils and } \\
\text { fats }\end{array}$ & $\begin{array}{l}\text { Cases } \\
\text { Controls }\end{array}$ & $\begin{array}{l}38 \\
35\end{array}$ & $\begin{array}{l}31 \\
35\end{array}$ & $\begin{array}{l}31 \\
40\end{array}$ & & $1 \cdot 0$ & $1 \cdot 2$ & $\approx 0 \cdot 27$ \\
\hline
\end{tabular}

* See Table 1 for definition of groups; † Levels are based on marginal medians, tertiles or quartiles on the basis of convenience (level 1 is the lowest and level 4 the highest); $\ddagger$ Adjusted by logistic regression for sex, age and socio-economic status. 
Table 3 Distribution of 100 cases and 110 controls by monthly frequency of consumption of the six discriminatory food items

\begin{tabular}{lllllllll}
\hline Food item & & \multicolumn{1}{c}{ Frequency per month Adjusted $^{2}$} \\
& & 0 & 2 & 4 & 10 & 30 & for trend $^{*}$ \\
\hline Brown bread & Cases & 67 & 0 & 2 & 5 & 26 & $9 \cdot 1$ \\
& Controls & 46 & 0 & 0 & 6 & 58 & \\
\hline Cucumbers & Cases & 20 & 15 & 31 & 31 & 3 & $13 \cdot 4$ \\
& Controls & 16 & 9 & 23 & 42 & 20 & \\
\hline Lettuce & Cases & 16 & 31 & 32 & 20 & 1 & $17 \cdot 6$ \\
& Controls & 10 & 9 & 35 & 51 & 5 & \\
\hline Spinach & Cases & 64 & 23 & 12 & 1 & 0 & $6 \cdot 4$ \\
& Controls & 58 & 31 & 18 & 3 & 0 & \\
\hline Beef meat & Cases & 4 & 11 & 23 & 58 & 4 & $3 \cdot 9$ \\
& Controls & 7 & 20 & 40 & 42 & 1 & \\
\hline \multirow{2}{*}{ Lamb meat } & Cases & 37 & 38 & 13 & 12 & 0 & $8 \cdot 2$ \\
& Controls & 57 & 34 & 17 & 2 & 0 & \\
\hline
\end{tabular}

${ }^{*} \mathrm{p}<0 \cdot 01$ (except for beef meat - see text)

meaningful if the risk ratios cover a six units increase in the frequency of consumption, because a value of 4 indicates a consumption 'once a week' and a value of 10 indicates consumption 'at least twice a week' (but not every day). Because brown bread is frequently used 'every day' or 'not at all' monthly frequencies of 0 and 30 are contrasted for this food item. The relative risk estimates are shown in Table 4.

On the basis of the monthly frequency of consumption of the discriminatory food items a linear risk score can be calculated for all 210 subjects, using the logistic regression coefficients ( $\log$ odds ratios of Table 4). The distribution of cases and controls by the risk score, categorised into five groups based on the empirical marginal quintiles, is shown in Table 5. Although a certain bias has been introduced by calculating the score on

Table 4 Relative risks associated with increase in the frequency of consumption of the indicated food items from once to twice per week* (for brown bread, from never to every day $\left.{ }^{\dagger}\right)$

\begin{tabular}{ll}
\hline Food item & Relative risk \\
\hline Brown bread ${ }^{*}$ & 0.43 \\
Cucumbers* & 0.65 \\
Lettuce* & 0.55 \\
Spinach* & 0.40 \\
Beef meat* & 1.89 \\
Lamb meat* & 3.86 \\
\hline
\end{tabular}

* Relative risk of consumption at least twice per week compared to once a week.

† Relative risk of consumption every day compared to never.
Table 5 Distribution of 100 cases and 110 controls by a 'risk score' calculated on the basis of consumption of discriminatory food items

\begin{tabular}{lccc}
\hline Risk score & Cases & Controls & Relative risk \\
\hline 1 & 4 & 37 & $1 \cdot 0$ \\
2 & 12 & 30 & $3 \cdot 7$ \\
3 & 21 & 22 & $8 \cdot 8$ \\
4 & 28 & 14 & $18 \cdot 5$ \\
5 & 35 & 7 & $46 \cdot 3$ \\
Total & 100 & 110 & \\
\hline
\end{tabular}

the basis of the empirical coefficients of the most discriminatory food items the 50 -fold risk range illustrates convincingly the importance of dietary factors in diverticulosis.

The risk score is a summary indicator of the relative risk associated with a variable frequency of consumption of the discriminatory food items; as such, it may be introduced into the logistic regression and potential interactions with age and sex may be evaluted. In the present data there was no significant evidence of age- or sex-interaction. The association was slightly stronger among women than among men, but the excess strength was minimal, and could reflect an increased dietary accuracy on the part of women.

Several other variables were investigated after controlling for age, sex, socio-economic status and frequency of consumption of discriminatory food items, but none of them was significantly, or even suggestively, associated with diverticulosis. Among these variables were: consumption of beer, wine, or other alcoholic beverages, weight, use of laxatives, tobacco smoking, daily walk, regular practice of sports (cases reported slightly higher involvement in walking and sports) and frequency of evacuation (cases reported slightly higher average frequency of evacuation). In addition the importance of parity, age at first pregnancy, age at menarche and age at menopause was investigated among the female cases and controls, after controlling for age and socioeconomic status. There was no large, consistent or significant association with respect to age at first pregnancy, age at menopause and age at menarche, but parity was associated with a significantly increased risk of diverticulosis (data available on request).

\section{Discussion}

Diverticulosis, although rare among Africans and Orientals, is common in developed western societies. The condition is usually asymptomatic and only a small minority develops serious or life threatening complications $;{ }^{19}$ yet the high frequency 
of the disease transforms these small proportions into substantial numbers and diverticulosis is an important public health problem.

The present study was undertaken in a population with substantial variability in dietary habits, a situation that would be expected to increase the power of an observational epidemiologic study focusing on diet. On the other hand the present study has some design characteristics which call for some discussion. First, individuals with asymptomatic diverticulosis were not excluded from the control series. Some epidemiologists would argue that inclusion of such individuals in the control series is not only acceptable but even advisable ${ }^{20}$ (if there were no competing causes of death all controls would ultimately become cases, sooner or later, depending on the incidence of the disease under study), but, theory aside, the prevalence of diverticulosis in the adult Greek population ${ }^{3}$ (less than $10 \%$ ) is too small to be of practical significance. Second, controls were chosen from two hospitals rather than the single hospital from which cases arose, but there is neither theoretical nor empirical evidence for any systematic difference between the two control subgroups. It is also possible that symptoms due to irritable bowel syndrome were attributed to coexisting asymptomatic diverticulosis, ${ }^{21}$ but the extent of the resulting misclassification, although important in clinical terms, cannot introduce numerically substantial bias in the context of the present study. Nevertheless, in view of this possibility the findings of the present study should be thought of as strictly applicable to patients with the so called symptomatic diverticular disease. Lastly all the cases were symptomatic, even though they did not know that they had diverticulosis (or indeed, what diverticulosis means). Few doctors or lay persons in Greece, however, would recommend a change of fibre intake as a remedy for unspecified gastrointestinal symptoms, and, in any case, this possibility was carefully considered and excluded at the time of the interview.

The results of the present study support strongly the idea that diet is of major importance in the aetiology of diverticulosis. An increase of fibre intake (vegetables, brown bread and, to a lesser extent, potatoes and fruits) is associated with a reduction of the risk of symptomatic diverticulosis. ${ }^{4}$ Diverticulosis does not appear to be simply a 'fibre deficiency' disease, however, as several other dietary factors (mainly lamb and beef and, to a lesser extent, milk and milk products) contribute, in an independent and detrimental way, to the development of the symptomatic condition. Furthermore, the 'fibre deficiency' in patients with diverticulosis does not appear to operate through a prolongation of the intestinal transit time; this time has been reported to be, if anything, shorter in patients with diverticulosis, ${ }^{12}$ and our results concerning the frequency of bowel evacuation in cases and controls are compatible with this notion. The involvement of several dietary factors, including meat, in the aetiology of diverticulosis may help to explain why vegetarians have a much lower prevalence of diverticulosis than would have been expected on the basis of their fibre intake. ${ }^{7}$

The findings of the present study do not implicate factors other than those of dietary nature in the aetiology of diverticulosis, and do not support the related views expressed by Archampong et al, ${ }^{9}$ Davey ${ }^{10}$ and others. Furthermore, our findings do not corroborate the suggestive evidence in the date of Gear $\mathrm{et} \mathrm{al}^{7}$ that there is a sex interaction in the protective action of dietary fibre.

This work was supported by a grant from the Greek Ministry of Health. The statistical analysis reported in this paper was undertaken during the tenure by $\mathrm{A}$ Tzonou of a Research Training Fellowship awarded by the International Agency for Research on Cancer.

\section{References}

1 Brodribb AJM. Humphreys DM. Diverticular disease: three studies. Part I - Relation to other disorders and fibre intake. Br Med J 1976; 1: 424-30.

2 Almy TP. Howell DA. Diverticular disease of the colon. $N$ Engl J Med 1980; 302: 324-31.

3 Manousos ON, Vrachliotis G, Papaevangelou G, et al. Relation of diverticulosis of the colon to environmental factors in Greece. Am J Dig Dis 1973; 18: 174-6.

4 Painter NS, Burkitt DP. Diverticular disease of the colon: a deficiency disease of western civilization. $\mathrm{Br}$ Med J 1971; 2: 450-4.

5 Carlson AJ, Hoelzel F. Relation of diet to diverticulosis of the colon in rats. Gastroenterology 1949; 12: 108-15.

6 Garry RC. Diet and diverticulosis. Br Med J 1971; 2: 773 .

7 Gear JSS, Ware A, Fursdon P, et al. Symptomless diverticular disease and intake of dietary fibre. Lancet 1979; 1: 511-4.

8 Brodribb AJM. Treatment of symptomatic diverticular disease with a high-fibre diet. Lancet 1977; 1: 664-6.

9 Archampong EQ, Christian F, Badoe EA. Diverticular disease in an indigenous African community. Ann $R$ Coll Surg Engl 1978; 60: 464-70.

10 Davey WW. Diet and diverticulosis. Br Med J 1968; 1: 118.

11 Ornstein MH, Littlewood ER, Baird IM, Fowler J, North WRS, Cox AG. Are fibre supplements really 
necessary in diverticular disease of the colon? A controlled clinical trial. Br Med J 1981; 282: 1353-6.

12 Manousos ON, Truelove SC, Lumsden K. Transit times of food in patients with diverticulosis or irritable colon syndrome and normal subjects. $\mathrm{Br}$ Med J 1967; 3: 760-2.

13 Mendeloff AI. A critique of "fiber deficiency". Am J Dig Dis 1976; 21: 109-12.

14 Manousos O, Day NE, Trichopoulos D, Gerovassilis F, Tzonou A, Polychronopoulou A. Diet and colorectal cancer: a case-control study in Greece. Int $J$ Cancer 1983; 32: 1-5.

15 Breslow NE, Day NE. Statistical methods in cancer research. Vol. I. The analysis of case-control studies. IARC Scientific Publications No. 32. Lyon: International Agency for Research on Cancer, 1980.
16 Baker RJ, Nelder JA. The GLIM system: release 3. Oxford: Numerical Algorithms Group, 1978.

17 Davidson SS, Passmore R. Human nutrition and dietetics. Edinburgh: Churchill Livingstone, 1979.

18 Graham S, Dayal H, Swanson M, Mittelman A, Wilkinson G. Diet in the epidemiology of cancer of the colon and rectum. J Natl Cancer Inst 1978; 61: 709-14.

19 Almy TP, Naitove A. Diverticular disease of the colon. In: Sleisenger MH, Fordtran JS, eds. Gastrointestinal disease: pathophysiology, diagnosis, management. 3rd ed. Philadelphia, Pa: Saunders, 1983.

20 Miettinen OS. Estimability and estimation in casereferent studies. Am J Epidemiol 1976; 103: 226-35.

21 Thompson WG, Patel DG, Tao H, Nair R. Does uncomplicated diverticular disease cause symptoms? Dig Dis Sci 1982; 27: 605-8. 